\title{
IMPACTO DE LA PRISIÓN PREVENTIVA EN EL SISTEMA DE JUSTICIA PENAL PERUANO; TACNA, 2008 - 2013.
}

Impact of pre-trial detention in the Peruvian criminal justice system; Tacna, 2008 - 2013.

\author{
Wilber Alberto Chávez Torres ${ }^{1}$
}

\section{RESUMEN}

El presente trabajo de investigación se llevó a cabo con el propósito de determinar el impacto de la aplicación de la prisión preventiva en la eficiencia del sistema de justicia penal peruano en el distrito judicial de Tacna, 2008-2013. El trabajo corresponde a una investigación de tipo básica. Asimismo, el estudio es no experimental de corte transversal, de nivel descriptivo relacional. Para tal propósito se consideró la información obtenida a través de la aplicación de la Ficha de Observación, y, la Cédula de Entrevista; como instrumentos de medición de las variables en estudio. Los datos obtenidos se tabularon y analizaron mediante cuadros y figuras. Una vez finalizada la fase de análisis e interpretación de los resultados se precisó que a) La aplicación de la prisión preventiva, tendría relación favorable con el principio de inmediación, en los procesos seguidos en el distrito judicial de Tacna con la implementación del Nuevo Código Procesal Penal; y, b) La aplicación de la prisión preventiva incidiría significativamente en la protección de derechos fundamentales en los procesos seguidos en el distrito judicial de Tacna.

Palabras clave: Prisión Preventiva, Protección de Derechos Fundamentales, Principio de Inmediación, Garantías Procesales, Eficiencia, Sistema de Justicia Penal.

\section{ABSTRACT}

This research was conducted in order to determine the impact of the application of preventive detention in the efficiency of the Peruvian criminal justice system in the judicial district of Tacna, 2008-2013. The research work corresponds to a basic type. Also, the study is not experimental cross-sectional descriptive relational level. For this purpose the information obtained through the implementation of the Observation Form, and the Certificate of Interview was considered; as instruments for measuring the variables studied. The data were tabulated and analyzed by tables and figures. Once the phase of analysis and interpretation of the results indicated that a) the application of preventive detention, would have favorable relationship with the principle of immediacy, in proceedings in the judicial district of Tacna with the implementation of the new Code criminal; and, b) the application of preventive detention would impact significantly on the protection of fundamental rights in the proceedings in the judicial district of Tacna.

Keywords: Preventive Detention, Protection of Fundamental Rights, Principle of Immediacy, Procedural Guarantees, Efficiency, Criminal Justice System.

\section{INTRODUCCIÓN}

Entre las medidas cautelares personales que regula y debe regular un Código Procesal Penal respetuoso con un Estado Democrático de Derecho, la prisión preventiva debe ser la última alternativa, a la que se debe recurrir. Cualquier otra motivación o justificación de la prisión preventiva es incompatible con el derecho a la presunción de inocencia y la libertad personal. En el distrito judicial de Tacna los requerimientos de prisión preventiva fueron 136 en el 2008, 175 en el 2009, 175 en el 2010, 260 en el 2011, 304 en el 2012 y 378 en el 2013. Han sido declarados fundados en un $57 \%$ durante los 6 años, los infundados el $20 \%$, y terminación Anticipada el $22 \%$. La presente investigación analizará la aplicación de las diferentes normas en los procesos seguidos en el Distrito Judicial de Tacna y permitirá precisar la doctrina sobre la aplicación de la prisión preventiva. EI CENTRO DE ESTUDIO DE JUSTICIA DE LAS AMÉRICAS (CEJA 2010) señala que las audiencias previas al juicio oral constituyen la principal innovación del nuevo diseño procesal penal, y que la prisión preventiva no es ajeno a esta realidad(«Centro de Estudios de Justicia de las Américas», 2010). La aplicación de la prisión preventiva como medida cautelar en el Perú ha sufrido grandes cambios a partir de la implementación del nuevo código procesal penal de 2004. Es igualmente positivo que se esté cumpliendo con los plazos máximos establecidos, en especial el referente a la obligación de presentar al imputado frente a un juez prontamente (Chávez-Tafur, G, 2010). La prisión preventiva es un acto procesal dispuesto por una resolución judicial que produce 
una prisión provisional de la libertad personal del imputado, con el propósito de asegurar el desarrollo del proceso personal y la eventual ejecución de la sentencia o pena(Nayu, R., 2010). Víctor Cubas Villanueva, señala que la prisión preventiva es una medida coercitiva de carácter personal, provisional y excepcional, y agrega que este mandato está limitado a los supuestos que la ley prevé(Cubas, V., 2013). La prisión preventiva es la medida cautelar de carácter personal, cuya finalidad acorde con su naturaleza es la de garantizar el proceso en sus fines característicos y cumplimiento de la futura y eventual pena que pudiera imponerse(Reyes, V., 2007). La prisión preventiva consiste en la privación temporal de la libertad ambulatoria de una persona, mediante su ingreso a un centro penitenciario, durante la sustanciación de un proceso penal con el objeto de asegurar los fines del procedimiento(Horvitz, M. I, 2005). Ferrajoli aboga por un proceso sin prisión provisional, porque así no solamente se asegura la dignidad del ciudadano presunto inocente, sino también y sobre todo, por necesidades procesales, para que quede situado en piede igualdad conlaacusación (Ferrajoli, L., 2000).

Los Principios para la aplicación de la prisión preventiva deben desplegar su mayor exigencia en los casos de imposición de la prisión preventiva, por cuanto es la más aflictiva de todas las medidas cautelares personales existentes (Huerta, S., 2013). Estos principios son Legalidad y Jurisdiccionalidad, para que la limitación de derechos fundamentales sea constitucionalmente legítima resulta necesaria que en su adopción intervenga decisivamente una autoridad judicial (Peña, A., 2013). Se requiere que la ley configure un procedimiento jurisdiccional que lo habilite, esto es, con arreglo al artículo 336.1 del CPP de 2004 que se haya emitido la Disposición Fiscal de Formalización y que esta haya sido comunicada al Juez de la Investigación Preparatoria (Artículo 3 del CPP de 2004) (San Martín Castro, C., 2013). Si durante la tramitación de la causa la única parte acusadora o todas las partes acusadoras solicitasen la modificación de la medida de prisión preventiva o que se dejase sin efecto, la autoridad judicial estaría obligada a acordarlo, Prueba suficiente, se trata de una prueba que indique como muy probable la realización del hecho y la intervención del imputado (Miranda, 2013,p.123), Proporcionalidad que se consagra como principio general del ordenamiento jurídico en su conjunto con la finalidad básicamente de limitar, en cualquier ámbito -y especialmente en los que se vinculan con el ejercicio de los derechos fundamentales, la discrecionalidad en el ejercicio estatal de la actividad de control de toda clase de facultades de actuación(De La Mata, N., 2013). Cobra mayor relevancia en el ámbito penal, en cuanto es aquí donde se muestra una mayor injerencia del Estado en el terreno de los derechos fundamentales(Aguado, T., 2013), Juicio de idoneidad que implica que toda intervención en los derechos fundamentales debe ser adecuada para contribuir a la obtención de un fin constitucionalmente legítimo (Gonzalo, N, 2013). Es un principio relacional en el sentido de que compara dos magnitudes: los medios a la luz del fin (Barnes, J., 2013), Juicio de necesidad, denominado "de subsidiariedad", que impone de entre la totalidad de las medidas restrictivas que resulten idóneas la que signifique el menor grado de limitación a los derechos de la persona(Bernal, C., 2013), Instrumentalidad que proporciona un medio $\mathrm{O}$ instrumento destinado a la efectividad del proceso y la ejecución de la eventual sentencia. "De manera tal que cualquier utilización autónoma de la prisión preventiva, o su orientación a fines distintos a los del proceso en el que se dictó la convertirían en ilegítimas" (Peña, A, 2013), Provisionalidad donde la prisión preventiva solo es legítima en la medida en que continúen existiendo todos sus presupuestos, desaparecido alguno de estos, la prisión preventiva debe cesar (Bovino, A., 2013) y Debida motivación donde se pueda verificarse los requisitos de idoneidad, necesidad y proporcionalidad en sentido estricto. Se debe mostrar cuál es el peligro procesal que intenta afrontar; debe argumentar que el auto de prisión cautelar es la medida menos restrictiva de las igualmente idóneas para alcanzar la finalidad propuesta, y debe apelar a las concretas circunstancias del sujeto procesado para argumentar la posibilidad del peligro procesado que dice estar presente en el caso, así como la necesidad del mandato de prisión preventiva(Castillo, L., 2013). "La obligación formal del juez consiste en efectuar una especial motivación de la resolución limitativa del derecho fundamental a la libertad ...." (Gimeno ,V., 2007).

EI plazo razonable de la prisión preventiva, es sometida a la observancia de dos órdenes de requisitos de fondo: por un lado, a las causales de justificación y la duración de la medida (Oré, A., 2013). Este plazo razonable de la prisión preventiva forma parte del derecho fundamental al plazo razonable de duración del proceso penal en relación con el derecho a la libertad. (Cafferata, J., 2000).

\section{EL SISTEMA DE JUSTICIA PENAL}

\section{Análisis de la Doctrina Garantista}

"Garantía es una expresión del léxico jurídico con la que se designa a cualquier técnica normativa de tutela de un derecho subjetivo". Por garantía se entiende, en el lenguaje de los civilistas, un tipo de instituto, derivado del derecho romano; dirigido a asegurar el 
cumplimiento de las obligaciones y la tutela de los correspondientes derechos patrimoniales. (Ferrajoli, L., 2000). "La ampliación del significado del término garantías y la introducción del neologismo garantismo para referirse a las técnicas de tutela de los derechos fundamentales son, en cambio; relativamente recientes" (Ferrajoli, L., 2000).

Los derechos fundamentales, se encuentran en oposición a los derechos patrimoniales, (Ferrajoli, L., 2000).

Principios contenidos en el Título Preliminar del Nuevo Código Procesal Penal:
a) Tutela Judicial Efectiva
b) Inmediación
c) Publicidad
d) Oralidad
e) Plazo Razonable
f) El Principio de Imparcialidad
g) Presunción de Inocencia
h) Nen Bis In Idem
i) Principio Acusatorio
j) EI Derecho de Defensa
k) Principio de Contradicción
l) Principio de Concentración

Creemos que el NCPP 2004 ofrece grandes mejoras con respecto al viejo código procesal vigente en el Perú(Huamán, D., 2010). No existen delitos por los que se aplique prisión preventiva de forma obligatoria o automática - los Ilamados delitos inexcarcelablesy que una vez impuesta la medida cautelar, el juez únicamente revisará la decisión si es que media un pedido expreso de la defensa(Huerta, S., 2013).

\section{Objetivos}

a) Conocer en qué medida la prisión preventiva, cumpliría el principio de inmediación, establecido en el sistema judicial penal en los procesos seguidos en el distrito judicial de Tacna.

b) Conocer en qué medida la aplicación de la prisión preventiva, incidiría en la protección de derechos fundamentales en los procesos establecidos en el sistema judicial penal seguidos en el distrito judicial de Tacna.

\section{METODOLOGÍA}

La investigación es de tipo básica, jurídico-social, siendo de enfoque mixto. Se aplicó el método del análisis y de la síntesis y el método lógico inductivo. Diseño no experimental, descriptivo y explicativo que desarrolló a nivel del departamento de Tacna entre los años 2008 al 2013. La primera unidad de análisis fueron docentes universitarios, magistrados, abogados, y fiscales penales con una muestra final de 95 y la otra estuvo comprendida por los casos judiciales (expedientes judiciales) en los que se aplicó prisión preventiva resueltos en el distrito judicial de Tacna, 2008-2013 con un muestra final de 314 casos. Los instrumentos par la recolección de los datos fueron la ficha de análisis documental, el cuestionario para la encuesta, la cédula de entrevista y la ficha de observación.

\section{RESULTADOS}

En el $82 \%$ de los casos se observa que el Fiscal sustenta oralmente su pedido sin apoyos de escritos; el $75 \%$ utiliza un documento de apoyo para realizar su pedido; el $82 \%$ lee los fundamentos de su pedido de prisión preventiva; y, el $18 \%$ de los casos no lo hizo adecuadamente (Tabla 1).

Tabla 1: Oralidad

\begin{tabular}{lrrrrr}
\hline Oralidad: & & si & & no & Total \\
\hline $\begin{array}{l}\text { 1.El Fiscal sustenta oralmente } \\
\text { su pedido sin apoyos escritos }\end{array}$ & 256 & 82 & 58 & 18 & 314 \\
$\begin{array}{l}\text { 2.El Fiscal utiliza un } \\
\text { documento de apoyo para }\end{array}$ & 234 & 75 & 80 & 25 & 314 \\
$\begin{array}{l}\text { realizar su pedido } \\
\begin{array}{l}3 . \text { El Fiscal lee los } \\
\text { fundamentos de su pedido de } \\
\text { prisión preventiva }\end{array}\end{array}$ & 258 & 82 & 56 & 18 & 314 \\
\hline
\end{tabular}


En el $77 \%$ de los casos se observa que el fiscal sustentó los elementos que vinculan al imputado con el hecho; el $75 \%$ de los casos sustentó que la sanción a imponerse sería superior a 4 años de pena privativa de libertad; el $78 \%$ sustentó que los antecedentes y circunstancias del imputado obstaculizarían la actividad probatoria; el $68 \%$ sustentó que el imputado pertenece a una organización delictiva 0 puede reintegrarse a la misma; el $86 \%$ presentó los elementos de convicción orientadas exclusivamente al pedido de prisión preventiva; el $82 \%$ presentó y actuó elementos de convicción acerca de la posible responsabilidad del imputado.

Respecto a peligro de fuga, en el $87 \%$ de los casos se observa que el fiscal sustentó el no arraigo del imputado o su facilidad para sustraerse del proceso penal; el $77 \%$ que la pena que se espera del procedimiento sería grave; el $78 \%$ la importancia del daño y la actitud del imputado frente al daño y en el $68 \%$ sustentó sobre el comportamiento del imputado en el procedimiento o en otro anterior, acerca de su voluntad de someterse a la persecución penal.
Respecto a los presupuestos materiales, el $75 \%$ de los casos se observa que el defensor contradijo el sustento fiscal sobre los elementos que vinculan al imputado con el hecho, el $76 \%$ contradijo acerca de que la sanción al imponerse sería superior a 4 años de pena privativa de libertad; el $78 \%$ contradijo de que los antecedentes y circunstancias del imputado obstaculizarían la actividad probatoria; el $78 \%$ contradijo el sustento fiscal acerca de que el imputado pertenece a una organización delictiva o puede reintegrarse a la misma, el $77 \%$ rechazó la presentación y actuación de los elementos de convicción acerca de la posible responsabilidad del imputado; el $71 \%$ rechazó la presentación de elementos de convicción orientadas exclusivamente al pedido de prisión preventiva; el 78 solicitó otra medida cautelar que no sea prisión preventiva; el $68 \%$ solicitó que el Fiscal señale cuánto tiempo tomará la investigación.

Respecto a el Juez, en el $82 \%$ de los casos se observa que el juez escucha a las partes en la audiencia; en el $77 \%$ lee la carpeta fiscal en la audiencia (Tabla 02)

Tabla 2: Oralidad

\begin{tabular}{|c|c|c|c|c|c|}
\hline \multirow[t]{2}{*}{ Oralidad: } & \multicolumn{3}{|c|}{ si } & \multirow{2}{*}{$\begin{array}{l}\text { no } \\
\%\end{array}$} & \multirow[t]{2}{*}{ Total } \\
\hline & $f$ & $\%$ & $f$ & & \\
\hline $\begin{array}{l}\text { ¿El Juez escucha a las partes } \\
\text { en la audiencia? }\end{array}$ & 256 & 82 & 58 & 18 & 314 \\
\hline $\begin{array}{l}\text { ¿El Juez lee la carpeta fiscal en } \\
\text { la audiencia? }\end{array}$ & 243 & 77 & 71 & 23 & 314 \\
\hline
\end{tabular}

En el $71 \%$ de los casos se observa que el juez para resolver consideró los elementos que vinculan al imputado con el hecho; el $73 \%$ consideró que la sanción al imponerse podría ser superior a 4 años de pena privativa de libertad; el $77 \%$ consideró los antecedentes y circunstancias del imputado que podrían obstaculizar la actividad probatoria; el $70 \%$ consideró el que el imputado perteneciera a una organización delictiva, el $76 \%$ aceptó la presentación y actuación de elementos de convicción orientadas exclusivamente al pedido de prisión preventiva; el $68 \%$ aceptó la presentación y actuación de elementos de convicción acerca de la posible responsabilidad del imputado.

En el $81 \%$ de los casos se observa que el juez para decidir consideró el arraigo del imputado o su dificultad para estar oculto; el $81 \%$ consideró que la pena que se espera del procedimiento sería grave, el $77 \%$ consideró la importancia del daño y la actitud voluntaria del imputado frente al daño; y el $79 \%$ consideró el comportamiento del imputado en el procedimiento $\mathrm{o}$ en otro anterior, acerca de su voluntad de someterse a la persecución penal. En el $74 \%$ de los casos se observa que el juez en su resolución hizo una mención sucinta de la imputación; el $63 \%$ hizo mención sucinta de los fundamentos de hecho y el $77 \%$ de los fundamentos de derecho. El $78 \%$ invocó normas legales, el $68 \%$ decidió el pedido de prisión preventiva sobre la base de información no ofrecida por las partes.

En el $74 \%$ de los casos se cumplió adecuadamente con las garantías procesales; el $63 \%$ de los casos se impartió con equidad la justicia; y el $69 \%$ de los casos se dio una debida protección de los derechos fundamentales. Los resultados nos permiten concluir que en la mayoría de los casos judiciales de prisión preventiva se dio una adecuada protección de los derechos fundamentales, dando cumplimiento a las garantías procesales y con la equidad de justicia requerida (Tabla 3 ). 
Tabla 3: Protección de derechos fundamentales

\begin{tabular}{|c|c|c|c|c|c|}
\hline $\begin{array}{l}\text { Protección de derechos } \\
\text { fundamentales: }\end{array}$ & & si & & no & Total \\
\hline & $f$ & $\%$ & $f$ & $\%$ & \\
\hline $\begin{array}{l}\text { Se cumplió adecuadamente con } \\
\text { las garantías procesales }\end{array}$ & 233 & 74 & 81 & 26 & 314 \\
\hline e impartió con equidad la justicia & 198 & 63 & 116 & 37 & 314 \\
\hline $\begin{array}{l}\text { Se dio una debida protección de } \\
\text { los derechos fundamentales }\end{array}$ & 216 & 69 & 98 & 31 & 314 \\
\hline
\end{tabular}

\section{RESULTADOS RELEVANTES DEL CUESTIONARIO}

De los reactivos consultados, destacan principalmente que el $81 \%$ de abogados, el $80 \%$ de docentes, el $83 \%$ de los jueces; y, el $75 \%$ de los fiscales manifestaron que en los procesos penales con aplicación de la prisión preventiva el cumplimiento de los presupuestos procesales es adecuado (Tabla 4).

Tabla 4: En los procesos penales, el cumplimiento de los presupuestos procesales es adecuado:

\begin{tabular}{|c|c|c|c|c|c|c|c|c|}
\hline \multirow[b]{3}{*}{ Si } & \multicolumn{8}{|c|}{ Muestra } \\
\hline & \multicolumn{2}{|c|}{ Abogados } & \multicolumn{2}{|c|}{ Docentes } & \multicolumn{2}{|c|}{ Jueces } & \multicolumn{2}{|c|}{ Fiscales } \\
\hline & $\begin{array}{l}N^{0} \\
34\end{array}$ & $\begin{array}{r}\% \\
81\end{array}$ & $\begin{array}{l}N^{\circ} \\
12\end{array}$ & $\begin{array}{r}\% \\
80\end{array}$ & $\begin{array}{r}\mathrm{N}^{\circ} \\
5\end{array}$ & $\begin{array}{r}\% \\
83\end{array}$ & $\begin{array}{l}N^{\circ} \\
24\end{array}$ & $\begin{array}{r}\% \\
75\end{array}$ \\
\hline No & 6 & 14 & 2 & 13 & 1 & 17 & 6 & 19 \\
\hline $\begin{array}{l}\text { No sabe/No } \\
\text { opina }\end{array}$ & 2 & 5 & 1 & 7 & 0 & 0 & 2 & 6 \\
\hline TOTAL & 42 & 100 & 15 & 100 & 6 & 100 & 32 & 100 \\
\hline
\end{tabular}

El $79 \%$ de abogados, el $60 \%$ de docentes, el $67 \%$ de los jueces; y, el $69 \%$ de los fiscales manifestaron que, en los procesos penales con aplicación de la prisión preventiva, los elementos de convicción presentados son adecuados.

El $83 \%$ de abogados, el $67 \%$ de docentes, el $83 \%$ de los jueces; y, el $81 \%$ de los fiscales manifestaron que en los procesos penales con aplicación de la prisión preventiva el sustento de la pena probable superior a 4 años de privación de libertad es adecuada.

El $95 \%$ de abogados, el $60 \%$ de docentes, el $67 \%$ de los jueces; y, el $91 \%$ de los fiscales manifestaron que en los procesos penales con aplicación de la prisión preventiva el sustento del peligro procesal presentado es adecuado.

El $81 \%$ de abogados, el $67 \%$ de docentes, el $67 \%$ de los jueces; y, el $94 \%$ de los fiscales manifestaron que en los procesos penales con aplicación de la prisión preventiva el sustento de peligro de fuga presentado es adecuado (Tabla 5).

El $83 \%$ de abogados, el $60 \%$ de docentes, el $67 \%$ de Ios jueces; y, el $88 \%$ de los fiscales manifestaron que en los procesos penales la aplicación de la prisión preventiva es adecuada.

Tabla 5: Aplicación de la prisión preventiva.

\begin{tabular}{lrrrrrrrr}
\hline & \multicolumn{10}{c}{ Muestra } \\
\cline { 2 - 10 } & \multicolumn{1}{c}{ Abogados } & \multicolumn{1}{c}{ Docentes } & Jueces & \multicolumn{3}{c}{ Fiscales } \\
\cline { 2 - 10 } & $N^{\circ}$ & $\%$ & $N^{\circ}$ & $\%$ & $N^{\circ}$ & $\%$ & $N^{\circ}$ & $\%$ \\
Si & 35 & 83 & 9 & 60 & 4 & 67 & 28 & 88 \\
No & 6 & 14 & 6 & 40 & 2 & 33 & 4 & 13 \\
No sabe/No & 1 & 2 & 0 & 0 & 0 & 0 & 0 & 0 \\
opina & & & & & & & & \\
TOTAL & 42 & 100 & 15 & 100 & 6 & 100 & 32 & 100 \\
\hline
\end{tabular}

El $93 \%$ de abogados, el $73 \%$ de docentes, el $67 \%$ de los jueces; y, el $69 \%$ de los fiscales manifestaron que en los procesos penales con aplicación de la prisión preventiva el juzgamiento es inmediato. 
El $86 \%$ de abogados, el $53 \%$ de docentes, el $67 \%$ de los jueces; y, el $91 \%$ de los fiscales manifestaron que con la aplicación de la prisión preventiva los procesos penales se realizan con celeridad.

El $81 \%$ de abogados, el $67 \%$ de docentes, el $83 \%$ de los jueces; y, el $81 \%$ de los fiscales manifestaron que en los procesos penales con aplicación de la prisión preventiva la protección de los derechos fundamentales es adecuada.

El $83 \%$ de abogados, el $60 \%$ de docentes, el $67 \%$ de Ios jueces; y, el $88 \%$ de los fiscales manifestaron que en los procesos penales con aplicación de la prisión preventiva el juzgamiento es oportuno.

\section{RESULTADO DE LA ENTREVISTA A LOS MAGISTRADOS}

La entrevista fue aplicada a 5 magistrados

Respecto a si en los procesos penales con aplicación de la prisión preventiva se cumple adecuadamente los presupuestos procesales

\section{Magistrado 1:}

En los casos que no confluyan o no se perciban los tres prerrequisitos demarcados por la ley: esto es, que no existan suficientes elementos de convicción respecto a la presunta responsabilidad del imputado (fumus bonus comissi), que la pena probable no sea superior a 4 años y que no haya peligro procesal: peligro de fuga $o$ de entorpecimiento a la investigación (periculum in mora); el Juez de la Investigación Preparatoria (Juez de Garantías) no podrá ni deberá amparar el requerimiento de prisión preventiva ya que para su imposición de una medida cautelar tan gravosa y extrema deberá cumplirse rigurosamente los presupuestos procesales.

\section{Magistrado 2:}

Sí, pero en regular medida, ya que en las Audiencias de prisión preventiva se un control desproporcionado respecto del peligro de obstaculización y peligro de fuga.

\section{Magistrado 3:}

Teniendo en cuenta que el proceso penal se juzga con criterio de conciencia existe un gran margen interpretativo que maneja el juzgador y por ello los presupuestos son solo referenciales en la práctica.

\section{Magistrado 4:}

Sí, por cuanto el fiscal presenta el requerimiento cumpliendo los requisitos establecidos en el art.268 del N.C.P.P, y estos son revisados en la investigación preparatoria.

\section{Magistrado 5:}

No se cumple adecuadamente ya que el C.P.P en el art.268 señala que el presupuesto debe tener varias posiciones tales como: arraigo familiar, laboral, etc. , debiendo de primar el presupuesto por la gravedad de la pena del delito cometido.
Respecto a si en los procesos penales con aplicación de la prisión preventiva se presenta una adecuada motivación judicial

\section{Magistrado 1:}

Es factible considerar que en la mayoría de los procesos penales con aplicación de la prisión preventiva se cumple con una adecuada motivación judicial toda vez que para aplicar dicha medida extrema se deben de cumplir presupuestos procesales.

Magistrado 2:

En la mayoría de casos se presenta una motivación aparente ya que cada juez tiene una idea distinta de los sujetos procesales.

Magistrado 3:

La motivación en las resoluciones judiciales es una exigencia constitucional por lo que debe y tiene que estar presente en toda resolución judicial.

Magistrado 4:

No, por cuanto el juez tiene que resolver inmediatamente y ello resta eficiencia en la motivación judicial.

Magistrado 5:

No, puesto que los magistrados tienen diversos criterios para fundamentar en caso especial en lo referido al tercer presupuesto del art.268 CPP sobre arraigos.

Respecto a si en los procesos penales, la aplicación de la prisión preventiva es adecuada Magistrado 1:

Sí, la aplicación preventiva es una medida extrema que se requiere justificadamente de manera excepcional para casos graves y para aplicar a una persona se decidirá en audiencia oral, con la intervención de todas las partes, garantizando los principios de contradicción, inmediación, publicidad y celeridad.

Magistrado 2:

Sí, puesto se tiene presente que la finalidad de la prisión preventiva es la detención ya que es pertinente asegurar la presencia del investigado en juicio oral así como que no obstruya la actividad probatoria.

\section{Magistrado 3:}

Los niveles de restricción de derechos permiten que la prisión preventiva no sea exclusiva a efectos de tener presente al procesado en el juzgamiento.

\section{Magistrado 4:}

Sí porque es un mecanismo que permite asegurar el éxito de la investigación y que el proceso penal cumpla con su objetivo.

\section{Magistrado 5:}

Debe aplicarse solo para los delitos que tienen una pena grave y no debe estimarse los arraigos. 
Respecto a si en los procesos penales con aplicación de la prisión preventiva, se cumple el principio de inmediación

Magistrado 1:

$\mathrm{Se}$ ha podido observar en estos años de implementación de la reforma procesal penal peruana, al aplicar la prisión preventiva se han resuelto considerablemente los problemas en torno a la realización de audiencias y a la toma de decisiones dentro del principio de inmediación y celeridad procesal al resolver en audiencia los requerimientos de prisión preventiva.

Magistrado 2:

Sí, puesto que en la Audiencia en la mayoría de casos se cumple con resolver el caso.

Magistrado 3:

Sí, porque se cumple con sentenciar en el momento de la Audiencia, cumpliéndose de esa manera el principio de inmediación.

Magistrado 4:

Sí, por cuanto es el juez quien recoge las versiones de las partes, ya sea del acusador como el de la defensa, y luego cumple con resolver según lo dispuesto en la norma.

Magistrado 5:

No se cumple solo es aparente el principio de

inmediación, ya que muchas veces se otorga la

prisión preventiva por proceso.

Respecto a si en los procesos penales con aplicación de la prisión preventiva, se cumple con la protección de los derechos fundamentales

Magistrado 1:

La entrada en vigencia del nuevo código en un distrito judicial ha implicado la instauración de numerosos cambios en materia de justicia penal, dirigidos a encontrar el equilibrio entre una mayor eficiencia procesal, por un lado, y el pleno respeto por las garantías judiciales-constitucionales de sus actores, por el otro.

Magistrado 2:

Si en gran medida, ya que cada proceso cumple con distintas características.

Magistrado 3:

Sí, porque se cumple con los principios procesales, y la protección de los derechos fundamentales de las partes procesales.

Magistrado 4:

Sí, porque se cumple con aplicar los principios de celeridad, oportunidad e inmediación para la protección de las partes procesales.

Magistrado 5:

No, se cumple ya que la prisión preventiva debe ser una medida de excepción a la privación de la libertad.
Respecto a si en los procesos penales con aplicación de la prisión preventiva,

el juzgamiento es oportuno

Magistrado 1:

Consideramos que, en los procesos penales con aplicación de la prisión preventiva, el juzgamiento resulta oportuno teniendo en consideración los principios procesales que rigen.

Magistrado 2:

Sí, puesto se cumple estrictamente las garantías del juzgamiento.

Magistrado 3:

Sí, porque se cumple con resolver en la Audiencia y dentro de los plazos señalados por la norma.

Magistrado 4:

Sí, ya que el juzgado prioriza los procesos de reo en cárcel.

\section{Magistrado 5:}

No, porque en algunos casos las diligencias no se realizan en el tiempo previsto por la falta de implementación de laboratorios de investigación.

Respecto a si la aplicación de la prisión preventiva tuvo un impacto positivo en el sistema de justicia penal peruano

Sí. De ahí que en el propio texto del NCPP 2004 se reconozca el carácter acusatorio, oral, público y contradictorio del nuevo proceso, lo que da lugar un manejo eficiente sistema de justicia penal en nuestro país.

Magistrado 2:

Sí, pues es un medio eficaz que permite que muchos procesos concluyan y no terminen con contumacia por la figura de prescripción.

Magistrado 3:

Sí, porque se cumple con resolver los procesos dentro de lo previsto y señalado en la norma, garantizando la protección de los derechos de las partes procesales.

Magistrado 4:

Sí, puesto la justicia actúa rápidamente especialmente en casos de flagrante delito.

Magistrado 5:

Sí, por cuanto se cumple con aplicar la prisión preventiva con la oportunidad de acuerdo a lo señalado en la norma.

\section{DISCUSIÓN}

La aplicación de la prisión preventiva incidiría significativamente en la protección de derechos fundamentales establecido en el sistema judicial penal en los procesos seguidos en el distrito judicial de Tacna. Asimismo, la entrevista aplicada a los magistrados y el análisis de las estadísticas sobre la aplicación de la prisión preventiva; nos han permitido encontrar las evidencias necesarias para aceptar esta hipótesis. 
Estos resultados concuerdan con los estudios de CEJA (2010). En el estudio de investigación "La Prisión Preventiva en Perú. Estudio de 112 audiencias en 7 distritos judiciales con el Nuevo Código Procesal Penal, señala que las audiencias previas al juicio oral constituyen la principal innovación del nuevo diseño procesal penal, de forma que se superen las características negativas, tradicionalmente vinculadas a nuestro sistema judicial, como son la excesiva formalidad, la burocracia, la mera tramitación de escritos y, la lentitud en la decisiones y respuestas frente al delito y el crimen. El ámbito de la prisión preventiva no es ajeno a esta realidad.

La prisión preventiva, cumpliría eficientemente con el principio de inmediación establecido en el sistema judicial penal, en los procesos seguidos en el distrito judicial de Tacna. Asimismo, la entrevista aplicada a los magistrados y el análisis de las estadísticas sobre la aplicación de la prisión preventiva; nos han permitido encontrar las evidencias necesarias para aceptar la hipótesis.

Hay relación con los estudios de, Chavez-Tafur (Chávez-Tafur, G, 2010) que señala que: La aplicación de la prisión preventiva como medida cautelar en el Perú ha sufrido grandes cambios a partir de la implementación del nuevo código procesal penal de 2004. Es igualmente positivo que se esté cumpliendo con los plazos máximos establecidos, en especial el referente a la obligación de presentar al imputado frente a un juez prontamente, que permite la protección de sus derechos. Así también respaldan esta hipótesis el estudio de Ronal Nayu(Nayu, R., 2010), el cual señala que la prisión preventiva es un acto procesal dispuesto por una resolución judicial que produce una prisión provisional de la libertad personal del imputado, con el propósito de asegurar el desarrollo del proceso personal y la eventual ejecución de la sentencia $O$ pena. La presente investigación comprobó que la aplicación de la prisión preventiva tendría un impacto positivo en el sistema de justicia penal peruano, Tacna 2008-2013. Los resultados nos permiten concluir que en la mayoría de los casos judiciales de prisión preventiva se dio una adecuada protección de los derechos fundamentales, dando cumplimiento a las garantías procesales y con la equidad de justicia requerida. En congruencia CEJA (2010), señala que las audiencias previas al juicio oral constituyen la principal innovación del nuevo diseño procesal penal, de forma que se superen las características negativas, tradicionalmente vinculadas a nuestro sistema judicial, como son la excesiva formalidad, la burocracia, la mera tramitación de escritos y, la lentitud en la decisiones y respuestas frente al delito y el crimen. El ámbito de la prisión preventiva no es ajeno a esta realidad. Adicionalmente, Gabriel Chávez-Tafur(Chávez-Tafur, $G$, 2010). señala que la aplicación de la prisión preventiva como medida cautelar en el Perú ha sufrido grandes cambios a partir de la implementación del nuevo código procesal penal de 2004. Es igualmente positivo que se esté cumpliendo con los plazos máximos establecidos, en especial el referente a la obligación de presentar al imputado frente a un juez prontamente, que permite la protección de sus derechos. Asimismo, la prisión preventiva es un acto procesal dispuesto por una resolución judicial que produce una prisión provisional de la libertad personal del imputado, con el propósito de asegurar el desarrollo del proceso personal y la eventual ejecución de la sentencia o pena(Nayu, R., 2010).

La reforma procesal penal está teniendo un impacto significativo en la aplicación racional y sustentada de la prisión preventiva, lo que se visualiza como un proceso positivo y alentador para el mejoramiento de la calidad de servicio judicial y la protección de los derechos fundamentales en el en el distrito judicial de Tacna, 2008-2013.

La Prisión Preventiva, es una medida coercitiva cautelar personal, prevista por nuestro nuevo Código Procesal Penal. que eventualmente se puede imponer a una persona sujeta a una Investigación Preparatoria, en los casos en que así lo requiera el proceso, para los fines de asegurar el desarrollo de la investigación, la vinculación del imputado a la misma y al Juzgamiento, que de ser el caso constituirá la culminación del proceso. En tal sentido, es: Una medida coercitiva, es decir que restriñe, limita, coerciona la libertad. Sólo se podrá aplicar, siempre y cuando se cumplan concurrentemente los requisitos establecidos por la ley, por la norma procesal penal para su imposición. la Prisión Preventiva no es pues en modo alguno una condena adelantada, sino una medida cautelar procesal, excepcional y provisional. Es en esencia la medida coercitiva personal más intensa que puede sufrir una persona. Susana Castañeda Otsu siguiendo a tratadistas como Sanguine, señala: que es una medida de coacción que representa la injerencia más grave que puede ejercer el poder estatal en la libertad individual. Con el Nuevo Código Procesal Penal, hasta el momento ha originado, de acuerdo con la información estadística, efectos interesantes, como la mayor atención de los casos presentados, una disminución sensible en el tiempo de tramitación de los procesos y un uso racional y ponderado de la prisión preventiva, lo que se refleja en una mejora sustancial en la situación jurídica de la población penitenciaria, garantizando la protección de los derechos fundamentales. 


\section{BIBLIOGRAFÍA}

Aguado, T. (2013). El principio de proporcionalidad en el derecho penal. En E. VILLEGAS PAIVA, La Detención y la Prisión Preventiva en el Nuevo Código Procesal Penal (pág. 96-113). Lima: El Búho.

Barnes, J. (2013). Introduccion al Principio de proporcionalidad en el derecho comparado y Comunitario. En E. VILLEGAS PAIVA, La detención y la prision preventiva en el nuevo Código Procesal Penal (pág. 116). Lima : E L Buho.

Bernal, C. (2013). El Principio de Proporcionalidad de la legislación Penal. En E. VILLEGAS PAIVA, La detención y la prisión preventiva en el nuevo Código Procesal Penal (pág. 117-118). Lima: El Buho.

Bovino, A. (2013). El encarcelamiento preventivo en los tratados de derechos humanos. En E. VILLEGAS PAIVA, La detención y la prisión preventiva en el nuevo Código Procesal Penal (pág. 123-124). Lima: El Buho.

Cafferata, J. (2000). La prueba en el proceso penal. Buenos Aires: De Palma,p.119.

Castillo, L. (2013). Criterios de interpretación para evaluar la constitucionalidad del mandato de detención. En E. VILLEGAS PAIVA, La detención y la prisión preventiva en el nuevo Código Procesal penal (pág. 131).

Centro de Estudios de Justicia de las Américas. (2010). Recuperado 1 de julio de 2017, a partir de http://w1.cejamericas.org/59-prision-preventiva-ymedidas-cautelares

Chávez-Tafur, G. (2010). La prisión preventiva en Perú, ¿medida cautelar o anticipo de la pena?.

Cubas, V. (2013). Las Medidas de Coerción. Lima: APP.

De La Mata, N. (2013). Aspectos nucleares del concepto de proporcionalidad de la intervención penal. En E. VILLEGAS PAIVA, La Detención y la Prisión Preventiva en el Nuevo Código Procesal Penal (pág. 101-112). Lima : El Búho.

Ferrajoli, L. (2000). Derecho y razón. Teoría del galantismo penal. México: Trota.p.73-83 y 100,173183.
Gimeno ,V. (2007). Los derechos fundamentales y su protección jurisdiccional, Madrid: Trota, p.100.

Gonzalo, N. (2013). El principio de proporcionalidad en el derecho Procesal español. En E. VILLEGAS PAIVA, La detencion y la prision preventiva en el nuevo Código Procesal Penal (pág. 117). Lima : El Buho .

Horvitz, M. I. (2005). Derecho Procesal Penal Chileno. Santiago: Editorial Jurídica de Chile,p.136144.

Huamán, D. (2010). Sobre la Integración de la dogmática sustantiva y el proceso penal: El caso de la conclusión anticipada del debate oral. Lima: Gaceta Penal \& Procesal Penal,p.198.

Huerta, S. (2013). El derecho fundamental a la legalidad en el Nuevo Código Procesal Penal de 2004. En E. VILLEGAS PAIVA, La Detención y la Prisión Preventiva en el Nuevo Código Procesal Penal (pág. 100-106). Lima: El Búho.

Nayu, R. (2010). La prisión preventiva en el nuevo código procesal penal. Buenos Aires: Casa, p.81.

Oré, A. (2013). Las medidas cautelares personales en el proceso penal peruano. En E. VILLEGAS PAIVA, La Detención y la Prisión Preveniva en el Nuevo Código Procesal Penal (pág. 115). Lima.

Peña, A. (2013). La libertar por exceso de detención. El derecho de ser juzgado en un plazo razonable. En E. VILLEGAS PAIVA, La Detención y la Prisión Preventiva en el Nuevo Código Procesal Penal (pág. 109). Lima: El Búho.

Peña, A. (2013). La libertar por exceso de detención. El derecho de ser juzgado en un plazo razonable. En E. VILLEGAS PAIVA, La Detención y la Prisión Preventiva en el Nuevo Código Procesal Penal (pág. 109). Lima: El Búho.

Reyes, V. (2007). Las medidas de coerción procesal personal en el NCPP del 2004. Gaceta Jurídica , 183.

San Martín Castro, C. (2013). Búsqueda de pruebas y restricción de derechos: registros e intervenciones corporales. En E. VILLEGAS PAIVA, La Detención y la Prisión Preventiva en el Nuevo Código Procesal Penal (pág. 108). Lima: El Búho.
Recibidos: 24/ 01 / 17

Aceptado para publicación: 09 / 06 / 17 